\title{
Management of Ventral Hernia Repair Laparoscopically -An Institutional Study of 35 Patients
}

\author{
Dr. Sumita Jain, MS, FICS, FAIS, FIAGES, Dr. Lakshman Agrawal, MS, FICS, FIAGES, Dr. Vivek \\ Rajan", MBBS, Dr. Ashutosh Pancholi, Ms, Dr. Rambabu Meena, MS, Dr. Devesh Bhomia, MS, \\ Dr. Chandra Shekhar Sharma, MBBS, Dr. Vinod Ghorela, MBBS, Dr. Deeksha Mehta, MS \\ Department of General Surgery, SMS Hospital, Jaipur, India
}

*Corresponding Author: Dr Vivek Rajan, Jr-3 Department of General Surgery, SMS Medical College, Jaipur, India.

\begin{abstract}
Background: Ventral hernia is commonly repaired by the open mesh method. However, since the introduction of the laparoscopic technique, it is increasingly becoming the method of choice for treating ventral hernia. The purpose of this study was to systematically review the literature, analyse the results of Laparoscopic repair of ventral and to ascertain its role.
\end{abstract}

Materials and Methods: Laparoscopic ventral hernia repair was performed for 35 patients. Patients unfit for general anaesthesia, patients posted for open repair were excluded. All operations were performed by a single consultant surgeon for 36 months. Pre-operative patient demographics were noted. Intra-operative and postoperative data were recorded and analysed.

Discussions: The technique for laparoscopic ventral hernia repair depends on the shape, size, location, number, recurrence, and symptoms of the hernia. Computed tomography $(C T)$ is the most accurate method for identifying these factors.

Results: 22 men (63\%) and 13 women (37\%) were included in this study. The mean age was 48.91 years. The mean hospital stay was 2.142 days. The mean BMI was 26.59 (range 21-47). The morbidity rate was $0 \%(0$ complications).

Conclusion: The results suggest laparoscopic repair of ventral hernia is an effective procedure. Faster recovery and shorter patient stay - makes it a feasible alternative to open repair.

\section{INTRODUCTION}

A ventral hernia is defined as a fascial defect in the anterior abdominal wall excluding the inguinal hernia. Multiple aetiologies predispose to the development of the defect, based on which ventral hernias can be broadly classified as congenital and acquired or in some cases as primary or secondary ventral hernias. Primary ventral hernias are subclassified as epigastric, Umbilical, Spigelian, lumbar hernia, etc. The secondary ventral hernias include incisional hernia, traumatic hernia, etc. Ventral hernias are also classified under European Hernia Society into medial and lateral. The medial hernias are subclassified into subxiphoid, epigastric, umbilical, infra-umbilical, suprapubic. The lateral hernias are subclassified into subcostal, femoral hernia, iliac, lumbar. The literature describes various natural weak points in the abdominal wall which include umbilicus, semilunar line, ostomy sites, bilateral inguinal regions, and oesophageal hiatus (1). This is because the anterior abdominal wall is very diverse in the way it is constituted at different points. For an instance, when the midline is considered, above the umbilicus, the internal oblique envelopes the rectus muscle. Below the umbilicus up to the pubic symphysis, there is the arcuate line where all the muscles come in front of the rectus muscle. The transversalis fascia comes underneath the rectus at this point. $(2,3)$

The most common type of ventral hernia is the incisional hernia. The tissue strength will never be the same after trauma or abdominal surgeries especially laparotomies. The maximum tensile strength, it achieves is $80 \%$ of the previous 
maximum. Multiple other patient factors like age, gender, habitual factors, obesity also play a pivotal role in the creation of defect

Management of ventral hernia depends on the patient conditions, the time of presentation, the content, how complicated the hernia and lastly the surgeon's skills.

Elective surgery can be planned on uncomplicated or asymptomatic patients whereas one might have to opt for emergency surgery for a complicated case. Non-surgical management of abdominal wall hernias with the use of binders, trusses, or corsets is not considered to be effective. However, this can be the only option in a patient who is not a reasonable candidate for surgery $(4,5,6)$

Historically, the open method of hernia repair was the preferred method of choice as the surgical management with a focus on restoration of the anatomical integrity of the abdominal wall. The recurrence rate following such repairs was $31 \%$ to $54 \% .(1,2)$. Later the initiative to use mesh for securing the defect found a major decrease in the rate of recurrence, though it led to the origin of a newer complication - mesh infection. The introduction of the laparoscopic approach for ventral hernia repair has gained wider acceptance across the world. It has proved to be vital in the early and enhanced recovery post-surgery and patient satisfaction cosmetically. The recurrence rate has decreased to $3 \%$ following the adoption of a laparoscopic method $(7,8)$. A major hurdle that surgeons face is the associated complications following the laparoscopic approach. Various complications like bowel injury, seroma formation, port site hernia have been reported worldwide. These complications draw attention to the importance of appropriate patient selection for laparoscopic hernia repairs. In our study, we report the case series of 35 patients presented with different types of ventral hernia at different sites managed by Laparoscopic Intraperitoneal Onlay Mesh Repair.

\section{Patients And Methods}

35 Patients who presented with a ventral hernia and underwent laparoscopic ventral hernia repair from 2016-2019 were included in the study. All patients were preoperatively screened for comorbidities and were assessed for fitness for laparoscopic surgery. Patients who did not give consent for laparoscopic surgery and who presented with complicated hernias were not included in the study. Defect sizes more than 8 $\mathrm{cm}$ and lesser than $2 \mathrm{~cm}$ were excluded from the study owing to the complications associated with larger defects and the unnecessary need for mesh repair in the defects smaller than $2 \mathrm{~cm}$. All the patients underwent a CT scan abdomen preoperatively to assess the exact size of a defect, any other defects (swiss-cheese defect), any associated pathology, and contents of the hernia. Preoperative bowel preparation was done in all cases where bowel was a content of hernia. A prospective assessment was conducted over 36 months and a further follow-up study was done. Follow up ranged from 36 months to a minimum of 1 year.

Every patient's details were recorded in the proforma for age, sex, BMI, defect size, type of mesh used, duration of surgery, duration of hospital stay, and any intraoperative or postoperative complication.

\subsection{Procedure}

The patient is kept in a supine position with their arms tucked in. The trocar sites were decided based on the location of the defect. The midline and right side defects were approached by trocars on the left side and the left side hernias were approached from the right side. Three trocars were used for the procedure. One $12 \mathrm{~mm}$ port at the tip of 11 ribs in the anterior axillary line, one $10 \mathrm{~mm}$ port on the midclavicular line, one $5 \mathrm{~mm}$ port in the anterior axillary line in the iliac fossa. This is basically for all midline hernias, if a hernia is at a different site, the port position changes. Pneumoperitoneum of $12-14 \mathrm{~mm}$ of hg was created either near the umbilicus or at palmer's point and the peritoneal cavity was thoroughly inspected. The defect size and the hernial contents are assessed. Adhesiolysis was done always by sharp dissection preventing unnecessary bleeding and use of harmonic scalpel in cases where the bowel is not involved making sure no enterotomy is caused. Following adhesiolysis, an inspection of the bowel andthe omentum is done meticulously and the sac was not removed in any cases but a raw area was created all around the sac for the fibroblast ingrowth and. The defect size is appreciated after complete adhesiolysis and the size of the mesh was decided accordingly that it spreads all around the defect at least $3-5 \mathrm{~cm}$. The defect was not closed in any of the cases We used four different composite meshes - MERINEUM COMPOSITE MESH (polypropylene/ polylactide-caprolactone mesh), ETHICON PROCEED MESH (triple layer - Polypropylene 
+ PDS + ORC), BARD COMPOSIX (Polypropylene + ePTFE), and PARIETEX from COVIDIEN for intraperitoneal onlay mesh repair owing to the advantage of lesser postoperative complications. The mesh is sutured on the four ends and the centre before inserting through the bigger $12 \mathrm{~mm}$ trocar. Inside the peritoneal cavity, the mesh is positioned in a way such that the centre of the mesh covers the defective wall area. The pneumoperitoneum pressure is decreased to 8$10 \mathrm{~mm}$ of $\mathrm{Hg}$ before final packing the mesh to the anterior abdominal wall. Suture passing needle is inserted from outside and the sutures are pulled outside and tied outside on four ends and centre.Make sure the sutures are not very tight, It is just to pack the mesh to the anterior abdominal wall. Following enforcement by sutures, tacks are used to further strengthen the fixation. Tacks are applied in a double crown manner so that the bowel does not enter between the mesh and anterior abdominal wall. All the patients were given ball dressing postoperatively over the sac to prevent seroma. This dressing was continued for three weeks till the process of healing. Postoperatively no abdominal binders were suggested for patients.

\section{Results}

Laparoscopic ventral hernia repair was performed on 35 consecutive patients by a single surgeon over 36 months between 2016 2019 in the Department of General Surgery, SMS Hospital, Jaipur.

Table 1. Distribution of age

\begin{tabular}{|c|c|}
\hline Age & Frequency \\
\hline $30-45$ & 14 \\
\hline $46-60$ & 15 \\
\hline Above 60 & 6 \\
\hline
\end{tabular}

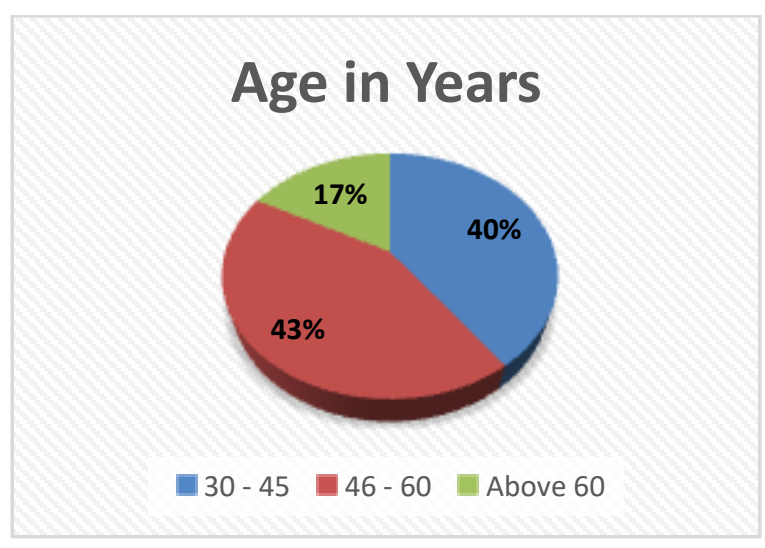

Figure 1. Distribution of Age

Out of 35 patients, 14 patients belonged to 3045,15 belonged to $46-60$ and 6 belonged to the above 60 age group. The mean age of presentation was 48.91 .

Table 2. Distribution of sex

\begin{tabular}{|c|c|}
\hline Sex & Frequency \\
\hline Male & 22 \\
\hline Female & 13 \\
\hline
\end{tabular}

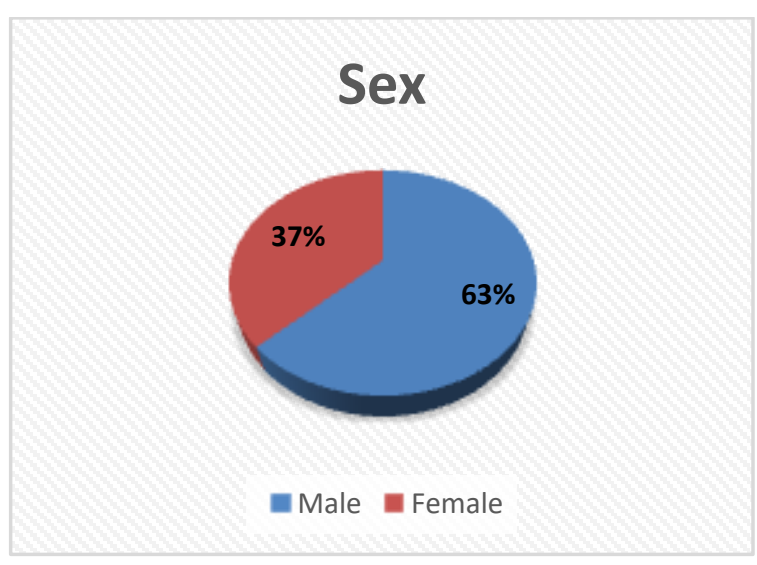

Figure 2. Distribution of sex

Among the 35 patients, $22(63 \%)$ were females and $13(37 \%)$ were males.

Table 3. Distribution of BMI $\left(\mathrm{Kg} / \mathrm{m}^{2}\right)$

\begin{tabular}{|c|c|}
\hline BMI & Frequency \\
\hline $20-25$ & 12 \\
\hline $26-30$ & 19 \\
\hline $31-35$ & 4 \\
\hline
\end{tabular}

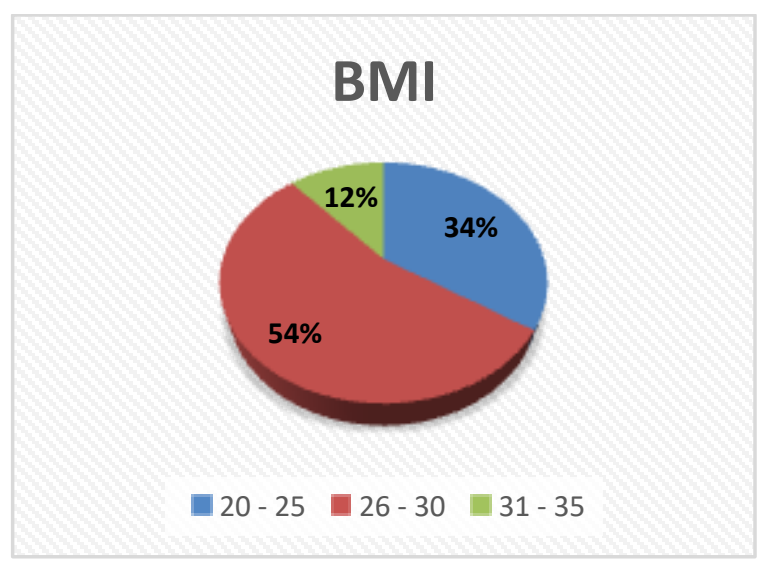

Figure 3. Distribution of $B M I\left(K g / m^{2}\right)$

4 patients out of 35 had a BMI between 31-35, 19 had a BMI between 26-30 and 12 had a BMI between 20-25. They had a mean BMI of 26.42 (23.2-33.4).

Table 4. Distribution of defect size $(\mathrm{cm})$

\begin{tabular}{|c|c|}
\hline Defect Size & Frequency \\
\hline $2-4$ & 20 \\
\hline $5-6$ & 11 \\
\hline $7-8$ & 4 \\
\hline
\end{tabular}




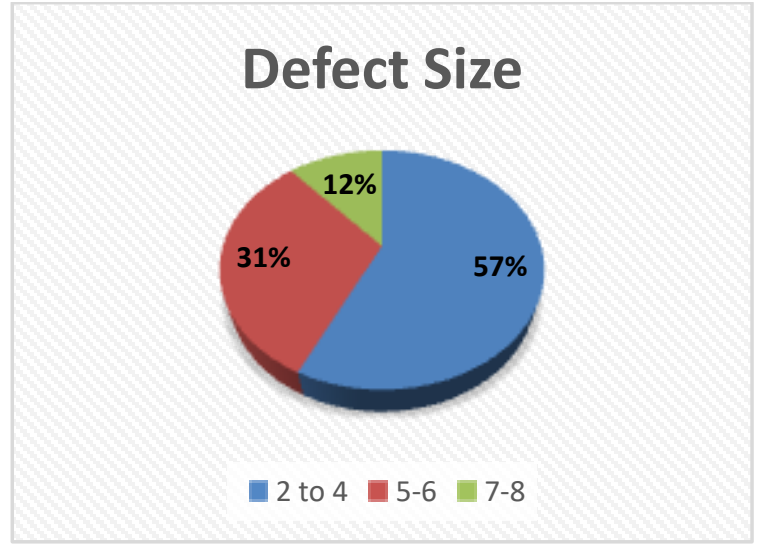

Figure 4. Distribution of defect size $(\mathrm{cm})$

20 patients had a defect size between $2-4 \mathrm{~cm}, 11$ patients had a defect size between $5-6 \mathrm{~cm}, 4$ patients had a defect size between $7-8 \mathrm{~cm}$. The mean defect size was 4.53 (range $2.5-8$ ) $\mathrm{cm}$.

Out of 35 cases of ventral hernia, 16 were incisional hernia, 10 were epigastric hernia, 4 were umbilical hernia, 2traumatic ventral hernia, 1 was port site hernia, 1 lumbar hernia and,1 recurrent hernia.

Table 5. Distribution of types of Ventral Hernia

\begin{tabular}{|l|c|c|}
\hline \multicolumn{1}{|c|}{ Type of Hernia } & Frequency & $\begin{array}{c}\text { Previous } \\
\text { Surgery }\end{array}$ \\
\hline UMBILICAL HERNIA & 4 & No \\
\hline EPIGASTRIC HERNIA & 10 & No \\
\hline INCISIONAL HERNIA & 16 & Yes \\
\hline LUMBAR HERNIA & 1 & No \\
\hline PORT SITE HERNIA & 1 & Yes \\
\hline $\begin{array}{l}\text { RECURRENT } \\
\text { HERNIA }\end{array}$ & 1 & No \\
\hline $\begin{array}{l}\text { TRAUMATIC } \\
\text { VENTRAL HERNIA }\end{array}$ & 2 & No \\
\hline
\end{tabular}

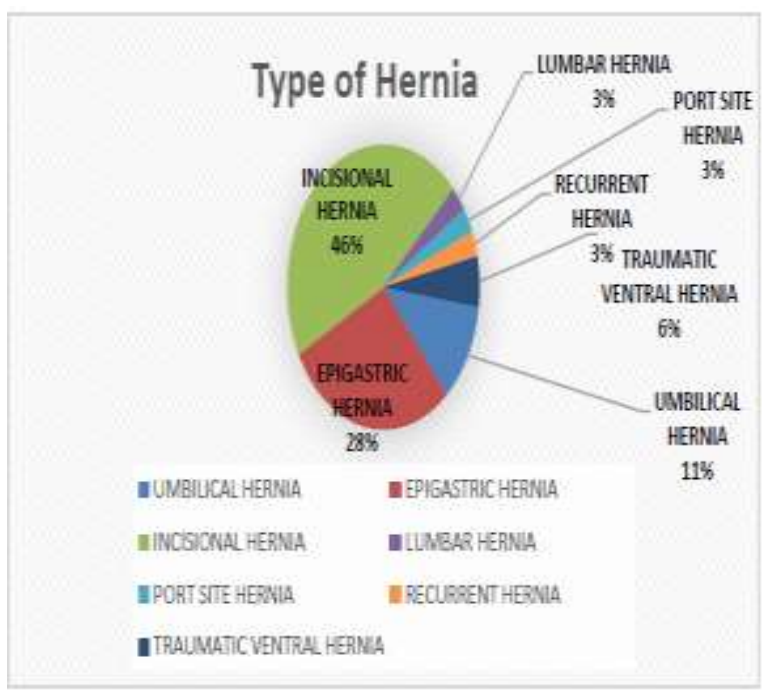

Figure 5. Distribution of types of Ventral Hernia
Table 6.Types of Incisional Hernia

\begin{tabular}{|l|c|}
\hline Previous Surgery (Incisional Hernia) & Frequency \\
\hline APPENDECTOMY & 3 \\
\hline CAESARIAN & 3 \\
\hline LAPAROTOMY & 7 \\
\hline Open Cholecystectomy & 2 \\
\hline Sigmoidostomy & 1 \\
\hline
\end{tabular}

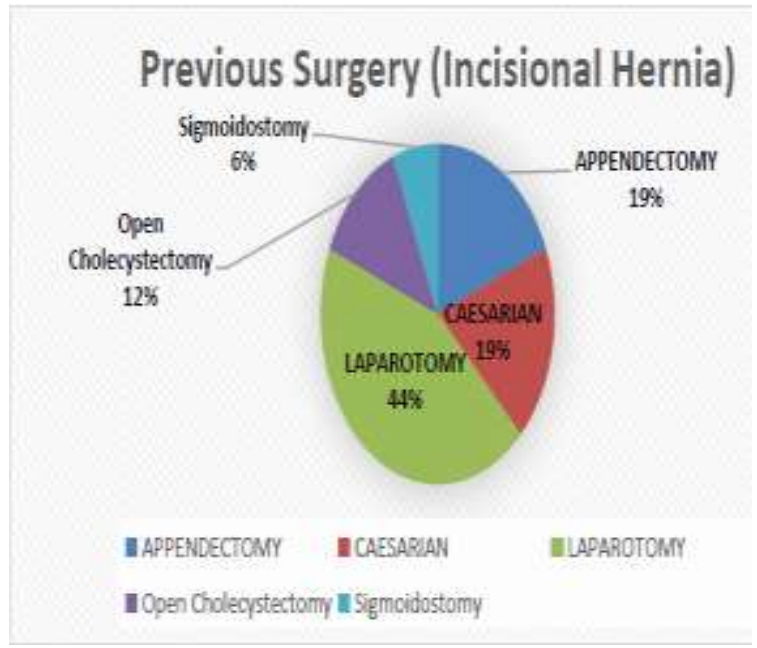

Figure 6. Types of Incisional Hernia

Amongst 16 cases of incision hernia, 7 were previous cases of midline laparotomy, 3 were of caesarean section, 3wereof appendectomy, 2 were of open cholecystectomy and 1 was of Sigmoidostomy.

Table 7. Content of Hernia

\begin{tabular}{|c|c|}
\hline Content & Frequency \\
\hline Bowel & 4 \\
\hline Fat & 23 \\
\hline Omentum & 8 \\
\hline
\end{tabular}

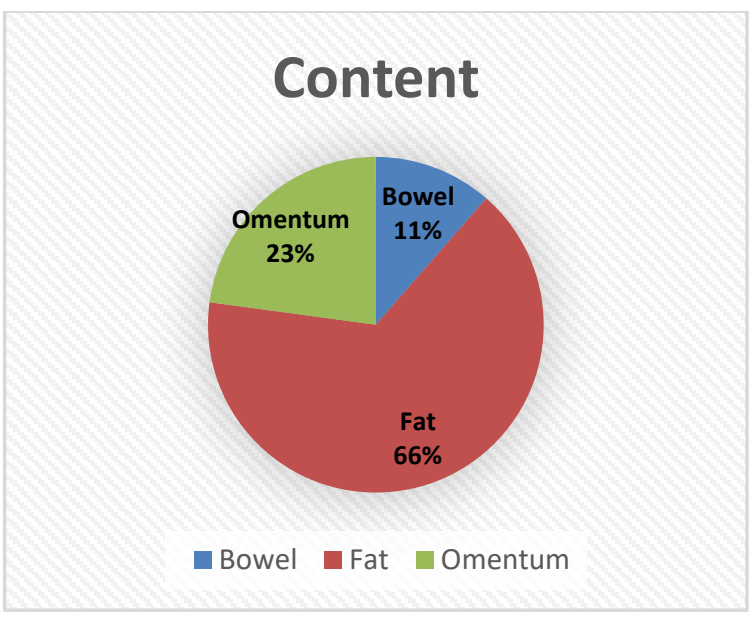

Figure 7. Content of Hernia

23 patients out of 35 patients had fat as the content of ventral hernia, 8 people had omentum and 4 people had bowel as the content. 
Table 8. Types of Composite Mesh Used

\begin{tabular}{|l|c|}
\hline \multicolumn{1}{|c|}{ Type Of Mesh } & Frequency \\
\hline $\begin{array}{l}\text { BARD COMPOSIX (Polypropylene + } \\
\text { ePTFE) }\end{array}$ & 5 \\
\hline COVIDIEN PARIETEX MESH & 4 \\
\hline $\begin{array}{l}\text { ETHICON PROCEED MESH (triple } \\
\text { layer - Polypropylene + PDS + ORC) }\end{array}$ & 13 \\
\hline $\begin{array}{l}\text { MERINEUM COMPOSITE } \\
\text { MESH(polypropylene/polylactide- } \\
\text { caprolactone mesh) }\end{array}$ & 13 \\
\hline
\end{tabular}

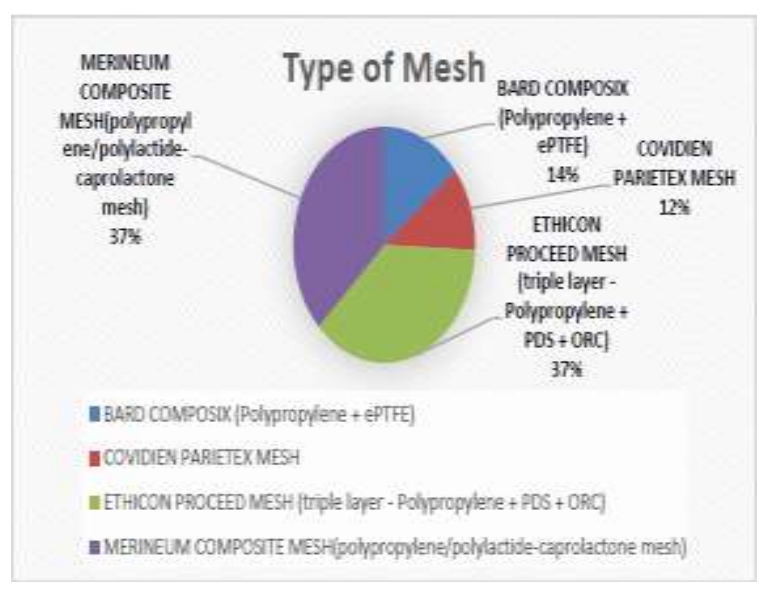

Figure 8. Types of Composite Mesh Used

Four different Composite Mesh were used for cases of intraperitoneal onlay mesh. Out of 35 patients, 13 (37\%) were repaired with MERINEUM COMPOSITE MESH, 13 (37\%) were repaired with ETHICON PROCEED, 5 (14\%) were repaired with BARD COMPOSIX and $4(12 \%)$ were repaired with COVIDIEN PARIETEX MESH.

All these patients underwent laparoscopic ventral hernia repair. The mean age of presentation was 48.91. Mean operating time taken by the surgeon was 65.25 minutes (74110).

All the patients had an uneventful postoperative period. They were allowed sips of fluids orally from the evening of the operative day. Mean hospital stay of patients was 2.142. Morbidity rate of patients was $0 \%$ with no complications in a follow up of 36 months.

\section{No Complications}

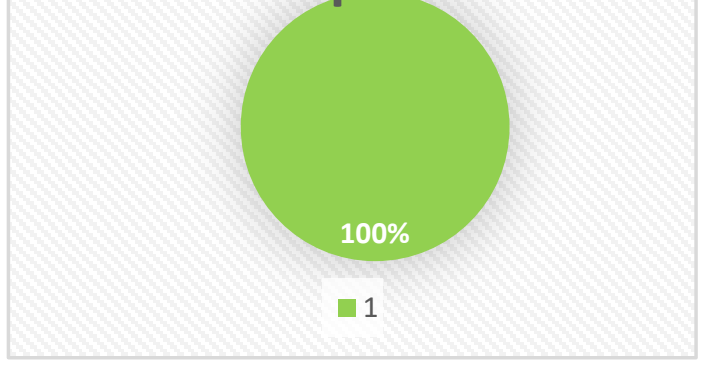

\section{DISCUSSION}

Laparoscopic repair of ventral hernia is becoming increasingly popular worldwide as expertise in the laparoscopic field has been improving. Laparoscopic repair was pioneered in studies from 1993 (9). Literature says various methods for creation of pneumoperitoneum using veress needle / open technique / optical viewing trocar / open Hassan technique. In our study, we created Pneumoperitoneum near umbilicus or through palmers point and used routine trocars without optical view and did not have any trocar related complications in 35 patients. The method of creation of pneumoperitoneum should be decided based on the surgeons experience and abilitiy to create pneumoperitoneum without causing bowel injury. Ben-haim et al in 2002 suggested the open technique of pneumoperitoneum and suggested the initial entry site to be "as far as possible from the hernia site" (10). Bageacu et al in 2002 suggested entry through veress needle and location of initial entry site typically on left anterior axillary line for a case of midline hernia. He suggested the use of 3-4 trocars (11). In our study we used three ports namely one 12 $\mathrm{mm}$, one $10 \mathrm{~mm}$, and one $5 \mathrm{~mm}$ port. Gillian et al in 2002 suggested insertion of optical viewing trocar in left subcostal region for midline hernia with the total use of 3-4 ports (12). The operative time needed for the surgery basically depends on the surgeon's expertise and how complicated the surgery is. In our study mean operating time was 65.25 minutes. Laparoscopic hernia repairs are reported to be longer than open mesh repair according to various studies $(13,14)$. In comparison to open methods, there is no time wasted for opening the flaps, suturing the mesh and placement of drains. In our study larger composite mesh was used for all the surgeries making sure that the defect is covered $5 \mathrm{~cm}$ all around the mesh. The usage of composite mesh in all the cases is must to prevent post-op bowel adhesions.

The complications of ventral hernia repair are broadly classified into major types and minor types. The major complications include bowel injury, excessive haemorrhage, mesh infection and recurrences. The minor ones are postoperative wound pain, seroma and ileus. According to literature seroma can be managed by ball dressing for two to three weeks. The seroma can be managed by a wait and watch policy (15). In our study, all patients were given ball dressing and thus no patients were advised 
abdominal binders and there were no reported cases of seroma formation. Literature says lesser postoperative pain after laparoscopic hernia repair than open ventral hernia repair $(16,17$, 18). Lesser postoperative pain in our case study is due to the use of absorbable tackers and tacks with lesser penetration. There were no instances of severe postoperative pain complained by the patient as we made sure that all the corner sutures were not very tight.

The most severe form of complication of laparoscopic repair is chance of enterotomy/bowel injury. Studies show that laparoscopic repair has more chances for injury to bowel than open method. (2.9\%vs $1.2 \%$ ) (19). In our study there were no reported cases of bowel injury among the patients owing to the better patient selection, reduced use of diathermy in bowel adhesions, surgeons expertise. In most of cases we preferred sharp dissection and harmonic scalpel for adhesiolysis which ensured haemostasis and lesser transmission of energy. Mesh infection is a complication ever since the introduction of the mesh. In our study there is no reported cases of mesh infection as this can be achieved by changing the gloves while handling the mesh and inserting the mesh comfortably through 12 $\mathrm{mm}$ port. We never used any abdominal drain as there was no need for it and the risk it carries for the mesh infection. The reason for no complication in our study is basically due to the strict patient selection, meticulous adhesiolysis, keeping the corner sutures loose, proper handling of mesh, and ball dressing postoperatively.

\section{CONCLUSION}

Laparoscopic ventral hernia repair can be costlier than its counterpart- Open Ventral Hernia Repair, but it has its own advantages like lesser morbidity, lesser post-operative pain. Lesser hospital stay, reduce recurrence rate, better cosmesis, decreased mesh infection and enhanced recovery post-surgery. It is a feasible and maybe a better option for the management of ventral hernia when done in an appropriate setup in appropriate hands.

\section{Prior PUblication}

NIL

\section{SUPPORT}

NIL

\section{CONFLICTS OF INTEREST}

NIL

\section{PeRMissions}

NIL

\section{BIBLIOGRAPHY}

[1] Smith J, Parmely JD. Ventral Hernia. [Updated 2020 Aug 10]. In: StatPearls [Internet]. Treasure Island (FL): StatPearls Publishing; 2020 Jan

[2] Aquina CT, Fleming FJ, Becerra AZ, Xu Z, Hensley BJ, Noyes K, Monson JRT, Jusko TA. Explaining variation in ventral and inguinal hernia repair outcomes: A population-based analysis. Surgery. $2017 \quad$ Sep;162(3):628639. [PubMed]

[3] Holihan JL, Alawadi ZM, Harris JW, Harvin J, Shah SK, Goodenough CJ, Kao LS, Liang MK, Roth JS, Walker PA, Ko TC. Ventral hernia: Patient selection, treatment, and management. CurrProbl Surg. 2016 Jul;53(7):307-54.

[4] Heniford BT. SAGES guidelines for laparoscopic ventral hernia repair. SurgEndosc. 2016 Aug;30(8):3161-2.

[5] Souza JM, Dumanian GA. Routine use of bioprosthetic mesh is not necessary: a retrospective review of 100 consecutive cases of intra-abdominal midweight polypropylene mesh for ventral hernia repair. Surgery. 2013 Mar;153(3):393-9

[6] de Vries HS, Smeeing D, Lourens H, Kruyt PM, Mollen RMHG. Long-term clinical experience with laparoscopic ventral hernia repair using a ParietexTM composite mesh in severely obese and non-severe obese patients: a single center cohort study. Minim Invasive Ther Allied Technol. 2019 Oct;28(5):304-308.

[7] H.H. Parker 3rd, J.M. Nottingham, R.P. Bynoe, M.J. YostLaparoscopic repair of large incisional hernias Am Surg, 68 (2002), pp. 530533

[8] B.T. Heniford, B.J. Ramshaw. Laparoscopic ventral hernia repair: a report of 100 consecutive cases SurgEndosc, 14 (2000), pp. 419-423

[9] Kua KB, Coleman M, MartinI, O’Rourke N. Laparoscopic repair of ventral incisional hernia. ANZ J Surg2002;72:296-9.

[10] Ben-Haim M, Kuriansky J, Tal R, Zmora O, Mintz Y, Rosin D, Ayalon A, Shabtai M (2002) Pitfalls and complications with laparoscopic intraperitoneal expanded polytetrafluoroethylene patch repair of postoperative ventral hernia. SurgEndosc 16:785-788 
[11] Bageacu S, Blanc P, Breton C, Gonzales M, Porcheron J, Chabert M, Balique JG (2002) Laparoscopic repair of incisional hernia: a retrospective study of 159 patients. SurgEndosc 16:345-348

[12] Gillian GK, Geis WP, Grover G (2002) Laparoscopic incisional and ventral hernia repair (LIVH): an evolving outpatient technique. JSLS 6:315-322

[13] Cobb WS, Kercher KW, Matthews BD, Burns JM, Tinkham NH, Sing RF, et al. Laparoscopic ventral hernia repair: a single center experience. Hernia 2006;10:236-42.

[14] Earle D, Seymour N, Fellinger E, Perez A. Laparoscopic versus open incisional hernia repair: a single-institution analysis of hospital resource utilization for 884 consecutive cases. SurgEndosc2006;20:71-5.
[15] Paton BL, Novitsky YW, Zerey M, Sing RF, Kercher KW, Heniford BT. Management of infections of polytetrafluoroethylene-based mesh. Surg Infect (Larchmt) 2007;8:337-41.

[16] Razman J, Shaharin S, Lukman MR, Sukumar $\mathrm{N}$, Jasmi AY. Initial experience of laparoscopic incisional hernia repair. Med $J$ Malaysia 2006;61:142-6.

[17] Golash V. Laparoscopic geometrical repair of ventral hernia. Surgeon 2006;4:33-8.

[18] Abir F, Eisenberg D, Bell R. Laparoscopic ventral hernia repair using a two $(5-\mathrm{mm})$ port technique. JSLS 2005;9:94-6.

[19] Pierce RA, Spitler JA, Frisella MM, Matthews BD, Brunt LM. Pooled data analysis of laparoscopic vs. open ventral hernia repair: 14 years of patient data accrual. SurgEndosc 2007;21: 378-86.

Citation: Vivek Rajan et al. Management of Ventral Hernia Repair Laparoscopically -An Institutional Study of 35 Patients. ARC Journal of Clinical Case Reports. 2020; 6(4):18-24. DOI: https://doi.org/10.20431/24559806.0604005.

Copyright: (C) 2020 Authors. This is an open-access article distributed under the terms of the Creative Commons Attribution License, which permits unrestricted use, distribution, and reproduction in any medium, provided the original author and source are credited. 